\title{
Escrever melhor com o método Cloze: um programa de intervenção para crianças
}

\section{Better writing with the Cloze method: an intervention program for children}

\author{
Dina Sereno, Inês Gomes \\ Universidade Fernando Pessoa
}

\begin{abstract}
Resumo
Este estudo tem como objetivo avaliar a eficácia do programa "Era uma vez..." no desempenho ortográfico de crianças do $4^{\circ}$ ano. Baseado no método Cloze, este programa contempla 8 histórias originais. As 65 crianças que participaram foram distribuídas pelos grupos experimental (GE; com intervenção) e controlo (GC; sem intervenção) e avaliadas em dois momentos (pré e pós-teste) com uma prova de escrita. Os resultados evidenciaram uma melhoria significativa do desempenho do pré para o pós-teste apenas no GE. No pós-teste, observaram-se diferenças intergrupo significativas, com vantagem para o GE, o que sugere tratar-se de um método promissor no desenvolvimento das habilidades ortográficas.
\end{abstract}

Palavras chave: ortografia, método Cloze, programa de intervenção, crianças do $1^{\circ}$ ciclo

\begin{abstract}
This study aims to analyse the effectiveness of the "Once upon a time..." program in spelling development of 4th grade children. Based on Cloze method, this program includes 8 original stories. Sixty-five children participated in this study; they were assigned to the experimental (EG, with intervention) and control (CG, without intervention) groups and evaluated in two moments (pre and post-test) with a spelling test. The results showed a significant improvement from pre to post-test in EG only. When post-test is considered, significant intergroup differences were observed, with advantage for the EG. These results highlight the importance of this method for writing acquisition.

Keywords: spelling, Cloze method, intervention program, school children
\end{abstract}

A linguagem escrita assenta num conjunto de símbolos e de convenções que todos nós, sujeitos alfabetizados, reconhecemos e utilizamos para nos expressar (Barbeiro, 2007). A sua mestria implica uma plena compreensão das propriedades deste sistema de notação, que, no caso do português, incluem aspetos como: a escrita efetua-se da esquerda para a direita e de cima para baixo, a partir de um repertório finito de letras, que não podem ser inventadas e que divergem de números e de outros símbolos; as letras, embora podendo assumir diferentes formatos (e.g., P, p, $P, p$ ), têm formas inalteráveis, pelo que pequenas variações produzem mudanças na sua identidade (e.g., p, q, b, d); a ordem das letras no interior da palavra não pode ser alterada; uma letra pode repetir-se no interior de uma palavra e em diferentes palavras; nem todas as letras podem ocupar certas posições no interior das palavras e nem todas as letras se podem juntar umas com as outras; as letras representam segmentos sonoros menores que as sílabas orais que pronunciamos; as letras têm valores sonoros fixos, apesar de muitas terem mais do que um valor sonoro e certos sons poderem ser grafados com mais do que uma letra; as sílabas contêm, pelo menos, uma vogal, podendo variar quanto às combinações entre consoantes e vogais (e.g., CV, CCV, CVC, V, VC, CCVC...), ainda que a estrutura que prevalece no português seja a sílaba CV (Morais, 2005; Leal, 2013). Segundo Leal (2013), será a compreensão destes e de outros princípios que regerá o processo de construção da escrita alfabética.

Apesar da aparente facilidade com que o fazemos, dominar a ortografia de uma língua e escrever corretamente nem sempre é fácil, uma vez que, como refere Veloso (2005), nem sempre se verifica uma correspondência regular, sistemática e unívoca entre os segmentos sonoros (fonemas) e os símbolos gráficos (grafemas). Os anos iniciais da aprendizagem assumem-se, deste modo, essenciais para uma correta apropriação da relação fonema-grafema.

A partir de um ensino formal e explícito, a criança vai sendo gradualmente exposta ao duplo sistema simbólico que caracteriza a linguagem falada e escrita, conhecimento este que lhe permitirá "transcrever um equivalente visual em um equivalente auditivo (leitura), ou o contrário, um equivalente auditivo em um equivalente visual (escrita)" (Guidetti \& Martinelli, 2007, p. 178). Nas ortografias ditas transparentes, ou superficiais, esta transcrição caracteriza-se por ser previsível, na medida em que as correspondências entre ambos os sistemas simbólicos tendem a ser regulares apresentando um elevado grau de consistência (i.e., um grafema só pode ser lido de uma única maneira e um fonema só pode ser escrito de uma única maneira; e.g., o grafema $f$ e o fonema /f/). No caso do português, esta regularidade pode ser de três tipos: derivada da correspondência biunívoca entre grafema e fonema, 
determinada por regra contextual ou derivada da condição morfológica. Já nas ortografias opacas, ou profundas, as correspondências são tipicamente de um-para-muitos, ocorrendo de modo arbitrário e inconsistente, isto é, sem que as mesmas sejam determinadas por qualquer regra (sendo, deste modo irregulares). Dito de outro modo, neste tipo de ortografia abundam os casos em que um grafema pode ser lido de diferentes maneiras e um fonema pode ser escrito de diferentes maneiras. Consequentemente, o seu domínio só será conseguido através da respetiva memorização da palavra irregular.

Aprender a ler e a escrever requer, deste modo, a apropriação deste duplo sistema simbólico, a partir da mobilização de recursos cognitivos vários. Trata-se de um processo desenvolvimental gradual, marcado pela presença de erros ortográficos nas fases iniciais da aprendizagem, que tendem a desaparecer com o aumento da escolaridade. A persistência de erros ortográficos ao longo dos anos deverá constituir um sinal de preocupação, na medida em que, pela sua natureza ou frequência, poderão comprometer significativamente a qualidade das produções escritas.

Atento à importância de se formar escritores competentes e criativos, os Novos Programas de Português apresentam uma secção que se debruça sobre os resultados que se esperam que os alunos atinjam, no final de cada um dos três ciclos do ensino básico, e que correspondem sumariamente à produção de textos de diferentes tipos em português padrão, com tema de abertura e fecho, e tendo em conta a organização em parágrafos e as regras ortográficas e de pontuação (Ministério da Educação, 2009). Atingir tal desiderato implica a conceção de atividades que, ancoradas em métodos e estratégias específicas, permitam favorecer, num primeiro nível, a escrita correta das palavras.

Um dos métodos que se apresenta promissor nesta matéria é o método Cloze. Este método teve a sua origem no ano de 1897, com os trabalhos do psicólogo alemão Ebbinghaus (Loh, \& Chia, 2013; Peltzman, 2015). No entanto, a sua divulgação mais ampla só se observou meio século mais tarde, quando Wilson Taylor (1953) utilizou este procedimento para avaliar o grau de acessibilidade/dificuldade da leitura de um determinado texto. Em termos gerais, este método consiste na apresentação de um texto onde determinados vocábulos foram omitidos e substituídos por um traço, competindo ao leitor a recuperação desses vocábulos de modo a restituir o sentido completo do texto (ibidem). Trata-se de um método muito versátil em formatos e conteúdos, que permite ao leitor tomar consciência da interatividade entre o seu eu e o texto, através de uma participação ativa na reconstrução do significado pretendido pelo autor (Cunha \& Santos, 2009).

A simplicidade deste método tem contribuído para uma utilização mais alargada a vários contextos e finalidades, tendo sido usado como instrumento para medir não só a compreensão de um texto, mas também a proficiência da língua (especialmente em bilingues), a competência linguística, e, até, para auxiliar e avaliar a eficácia da leitura e do ensino (Abreu, Garcia, Hora, \& Souza, 2017; Castro, 2008). Ainda assim, é com a finalidade de mensurar o nível de compreensão da leitura, na dupla perspetiva do diagnóstico e da intervenção, que o método Cloze tem vindo comummente a ser utilizado (Joly \& Piovezan, 2011; Mota \& Santos, 2014; Silva \& Santos, 2004). No entanto, se para alguns autores (e.g., Loh, \& Chia, 2013; Santos, 2004) os exercícios baseados no método Cloze se assumem fundamentais para a dinamização do processo de compreensão e consequente melhoria da aprendizagem, para outros (e.g., Kongsuwan Nakul, 2015) o preenchimento das lacunas não se reduz apenas à dimensão do significado da forma reconhecida, exigindo igualmente a ativação de componentes complexos de conhecimento das palavras.

O método Cloze, ao se direcionar para a compreensão leitora, apresenta-se como um recurso promissor para aprimorar as competências ortográficas já que, como sublinham Guidetti e Martinelli (2007), a leitura e a escrita são duas significações interdependentes, logo, influenciando-se mutuamente. Efetivamente, vários estudos têm evidenciado a existência de relação entre a compreensão leitora e a escrita. No entanto, permanecem ainda escassos os estudos que utilizam este método na avaliação ou na promoção das habilidades de escrita (para uma exceção cf. Guidetti \& Martinelli, 2007; Guimarães, 2011). Neste quadro, e no sentido de contribuir para uma melhor compreensão do papel deste método no desenvolvimento da ortografia, foi conduzido o presente estudo, que teve como finalidade avaliar a eficácia do programa de intervenção psicopedagógica intitulado "Era uma vez..." na aprendizagem da ortografia em crianças do $4^{\circ}$ ano de escolaridade.

\section{Método}

\section{Participantes}

Participaram no presente estudo 65 crianças do $4^{\circ}$ ano de escolaridade, de ambos os sexos e com idades compreendidas entre os 9 e os 10 anos (cf. Tabela 1). As crianças encontravam-se a frequentar escolas da Região Autónoma da Madeira, mais precisamente, da cidade do Funchal, tendo sido aleatoriamente distribuídas pelos grupos experimental (com intervenção) e de controlo (sem intervenção). Nenhum dos participantes apresentava histórico de retenções no seu percurso escolar nem estava referenciado como tendo Necessidades Educativas Especiais.

Tabela 1.

Caracterização dos participantes

\begin{tabular}{lcclc}
\hline \multirow{2}{*}{ Grupo } & \multicolumn{2}{c}{ Sexo } & & Idade \\
\cline { 2 - 3 } \cline { 5 - 6 } & Fem. & Masc. & & Média (DP) \\
\hline Experimental $(n=32)$ & 17 & 15 & & $9.47(0.51)$ \\
Controlo $(n=33)$ & 18 & 15 & & $9.30(0.47)$ \\
\hline
\end{tabular}

\section{Material}

Medida do pré e pós-teste. A avaliação do desempenho ortográfico das crianças no pré e pós-teste foi efetuada através da Prova Escrita e Regularidade 
(P44) que integra a versão portuguesa da bateria PALPA-P (Castro, Caló, Gomes, Kay, Lesser, \& Coltheart, 2007). Trata-se de uma prova de escrita por ditado, que analisa o efeito da regularidade ortográfica. Contém um total de 40 estímulos, dos quais 22 são palavras de ortografia regular e 18 de ortografia irregular. (Note-se que, ao contrário da referência que é feita na prova quanto ao número equitativo de palavras regulares e irregulares, 2 das 20 palavras de ortografia irregular foram por nós reclassificadas uma vez que, atualmente, fruto da alteração do acordo ortográfico, estas deixaram de o ser: tractor, baptismo).

Programa de intervenção "Era uma vez...". Este programa assenta em oito histórias infantis, de temas diversificados e adequados à idade e escolaridade dos participantes. Estas histórias foram construídas com base no método Cloze, tendo-se omitido, de forma sistemática, o décimo vocábulo. As palavras-alvo omitidas foram criteriosamente selecionadas em função da classe gramatical, da sua extensão e da regularidade ortográfica. No total, cada história contém 25 lacunas, apresentando, deste modo, uma dimensão compreendida entre 255 a 259 lexemas. As histórias diferem entre si quanto ao tipo de preenchimento das lacunas que é exigido à criança, encontrando-se organizadas em níveis de complexidade crescente. Na primeira história, é pedido ao participante que complete a lacuna escolhendo uma de duas palavras (homófonas) que são facultadas; na segunda história, a escolha é efetuada de entre três palavras concedidas; na terceira história, as 25 palavras omissas são apresentadas desordenadamente numa coluna vertical adjacente ao texto; na quarta história, 25 palavras omissas foram substituídas pelos respetivos desenhos e dispostos igualmente numa coluna vertical adjacente ao texto; na quinta história, foi concedida à criança a primeira letra da palavra a redigir; na sexta, cada letra da palavra omitida foi substituída por um traço; na sétima, o traço da lacuna é proporcional ao tamanho da palavra-alvo; e, por fim, na oitava história não foi concedida qualquer pista ao participante.

\section{Procedimento}

Na sequência da autorização da Secretaria Regional da Educação e dos Recursos Humanos da Região Autónoma da Madeira para a condução do presente estudo, foram contactados os diferentes intervenientes (diretores de escola, professores titulares de turma, alunos e encarregados de educação), tendo-lhe sido prestadas informações sobre os objetivos e metodologia do mesmo. A participação das crianças ficou sujeita à assinatura do consentimento informado pelos responsáveis legais.

$\mathrm{O}$ estudo iniciou-se com o pré-teste, tendo as crianças de ambos os grupos sido avaliadas com a prova de escrita e regularidade P44. Foi solicitado aos participantes que escrevessem numa folha A4 em branco, as palavras ditadas pelo investigador.

Recolhidos os dados do pré-teste, o grupo experimental foi submetido ao programa "Era uma vez", enquanto o grupo de controlo não foi alvo de qualquer intervenção durante esse período. As 8 sessões foram realizadas em grupo (no contexto da turma) com periodicidade semanal, durando, em média, 1 hora por sessão. As sessões foram estruturadas em três fases: escrita espontânea, correção e explicação da ortografia, e escrita após treino. Na primeira fase - escrita espontânea - a criança era convidada a preencher individualmente e sem ajuda a história dessa sessão. De seguida, era efetuada a correção da história, oralmente e no quadro, contabilizando-se os erros que cada criança tinha dado (de modo a se dispor de uma linha de base). Ainda nesta fase, e de maneira a evitar a repetição do erro, era fornecida uma explicação, sempre que possível, da razão pela qual as palavras teriam uma dada ortografia e não outra. Terminada esta fase de correção e explicação da ortografia correta, a criança era novamente convidada a preencher a história e a contabilizar os erros, comparando o seu desempenho com a linha de base. De salientar que quer na fase da escrita espontânea quer na fase da escrita após treino, não foram fixados tempos limite para a realização das atividades.

Decorridas as 8 semanas de implementação do programa, os participantes de ambos os grupos foram reavaliados, escrevendo novamente por ditado as palavras que integram a Prova Escrita e Regularidade (P-44).

\section{Resultados}

Foram efectuados testes $t$ de amostras independentes para analisar a homogeneidade dos grupos no pré-teste (grupo experimental e grupo de controlo) e para avaliar a eficácia do programa (T2-T1, isto é, subtração da média obtida no pós-teste à média obtida no pré-teste). Foi ainda realizado um teste $t$ de amostras emparelhadas para cada grupo (experimental e controlo) no sentido de analisar diferenças entre o pré e o pós-teste.

Homogeneidade dos grupos. Quando se considera o desempenho das crianças na prova P44 no primeiro momento de avaliação (T1, pré-teste), verifica-se uma ligeira vantagem do grupo de controlo em relação ao grupo experimental (cf. Tabela 2). Esta situação verificou-se tanto a nível global como separadamente para as palavras regulares e irregulares. No entanto, estas diferenças entre os grupos não atingiram significância $\left(t_{(63)}=-1.81\right.$, $n s$ para o total de palavras, $t_{(63)}=-1.30, n s$ para as palavras regulares e $t_{(63)}=-1.81$, ns para as palavras irregulares), o que atesta a homogeneidade da amostra. 
Tabela 2 .

Estatística descritiva por grupo quanto à exatidão ortográfica

\begin{tabular}{|c|c|c|c|c|c|c|}
\hline \multirow{2}{*}{ Prova P44 } & \multicolumn{3}{|c|}{ Grupo experimental $(n=32)$} & \multicolumn{3}{|c|}{ Grupo de controlo $(n=33)$} \\
\hline & T1 (pré-teste) & T2 (pós-teste) & $\mathrm{T} 2-\mathrm{T} 1$ & T1 (pré-teste) & T2 (pós-teste) & $\mathrm{T} 2-\mathrm{T} 1$ \\
\hline Palavras Regulares & $20.03(1.64)$ & $20.66(1.56)$ & $0.63(1.50)$ & $20.55(1.56)$ & $20.06(1.46)$ & $-0.48(1.39)$ \\
\hline Palavras Irregulares & $13.59(2.49)$ & $15.09(2.37)$ & $1.50(2.11)$ & $14.61(2.00)$ & $14.64(2.45)$ & $0.03(1.72)$ \\
\hline Total de Palavras & $33.59(3.65)$ & $35.72(3.61)$ & $2.13(2.86)$ & $35.12(3.14)$ & $34.70(3.56)$ & $-0.42(2.49)$ \\
\hline
\end{tabular}

Desempenho ao longo do tempo. Relativamente ao total de palavras da prova $\mathrm{P} 44$, o desempenho do grupo experimental melhorou do pré para o pós-teste (com um aumento médio de 2.13 respostas corretas), enquanto o desempenho no grupo de controlo diminuiu ligeiramente. Este efeito do Tempo na escrita correta das palavras foi apenas significativo no grupo experimental $\left(t_{(31)}=-4.20, p<.001\right.$ vs. $t_{(32)}=0.98, n s$, no grupo de controlo), deixando antever uma vantagem do método Cloze na exatidão da ortografia.

O mesmo padrão de desempenho foi observado na escrita de palavras regulares, com aumento do número de respostas corretas no grupo experimental e diminuição no grupo de controlo. Uma vez mais, as diferenças entre o pré e o pós-teste apenas atingiram significância no grupo experimental $\left(t_{(31)}=-2.36, p<\right.$ .001 vs. $\left.t_{(32)}=2.00, n s\right)$. Nas palavras irregulares, a melhoria do desempenho no grupo experimental foi mais expressiva do que nas palavras regulares, tendo-se igualmente observado uma melhoria significativa do desempenho ao longo do tempo $\left(t_{(31)}=-4.02, p=.025\right)$. No grupo de controlo, as palavras irregulares foram as únicas que beneficiaram com a passagem do tempo; ainda assim, as diferenças entre o pré e o pós-teste não foram significativas $\left(t_{(32)}=-0.10, n s\right)$.

Eficácia do programa. Quando se comparam ambos os grupos quanto aos ganhos médios obtidos a partir da diferença entre o pós-teste e o pré-teste (T2 - T1), verifica-se um padrão de desempenho inverso ao encontrado no pré-teste, tendo sido as crianças do grupo experimental aquelas que deram um maior número de respostas corretas. Esta diferença intergrupos atingiu valores significativos quer quando se considera a prova total $\left(t_{(63)}=3.838, p<.001\right)$, quer quando se consideram separadamente as palavras regulares $\left(t_{(63)}=3.093, p<\right.$ $.01)$ e irregulares $\left(t_{(63)}=3.081, p<.01\right)$.

\section{Discussão}

Os resultados observados no presente estudo sugerem a eficácia do programa "Era uma vez..." na correção ortográfica dos participantes. Quer quando se considera o total de palavras quer quando se consideram separadamente as palavras regulares e irregulares, o grupo experimental foi o único a melhorar o desempenho do pré-teste para o pós-teste, diferindo significativamente do grupo de controlo no final da intervenção. Considerando que ambos os grupos eram homogéneos no início do estudo, esta diminuição dos erros ortográficos no grupo experimental permite aventar quanto à utilidade do método Cloze nesta área, reforçando a ideia da versatilidade deste instrumento. Trata-se de um método simples, que integra inúmeras possibilidades de variações da técnica e que permite o seu emprego em diferentes conteúdos e para atingir diferentes objetivos. Tal característica tem a vantagem de permitir a supressão de categorias específicas de informação do texto, em função da finalidade pretendida pelo professor ou em função das dificuldades dos alunos (Santos, 2004).

No caso concreto do programa "Era uma vez..." importa enfatizar a intencionalidade que esteve na base da sua conceção. Ao se pretender estimular na criança o conhecimento da ortografia das palavras, as histórias foram construídas de modo a que a lacuna correspondesse a vocábulos com correspondências grafema/fonema regulares e/ou irregulares. Esta manipulação do segmento ortográfico-alvo, a par de uma implementação baseada na explicação da grafia das palavras e na repetição da atividade como forma de consolidar as aprendizagens, poderá ter estado na base do sucesso do programa.

No entanto, as limitações deste estudo aconselham a alguma prudência na interpretação destes resultados. Para além das questões associadas à dimensão da amostra, destaca-se a inexistência de medidas do funcionamento cognitivo que permitissem compreender melhor as características de ambos os grupos. Apesar de serem grupos homogéneos quanto a características sociodemográficas (idade, escolaridade, sexo) e quanto ao nível inicial de conhecimento ortográfico, nada se sabe quanto à homogeneidade ou heterogeneidade de variáveis cognitivas, como o conhecimento lexical, a memória e a atenção, entre outros. Ora, como nos dizem Abreu et al. (2017), o desempenho nos testes Cloze parece depender não só de fatores linguísticos, como o tipo de palavra omitida (lexical ou funcional), mas também de fatores não linguísticos, como a memória e a escolaridade, por exemplo.

Em jeito de conclusão, os resultados observados neste estudo, apesar de modestos, são promissores quanto às potencialidades dos programas estruturados a partir do método Cloze e que tenham como finalidade desenvolver habilidades ortográficas. A validação da respetiva eficácia constitui uma área emergente de investigação dada a escassez de estudos com esta finalidade.

\section{Referências}

Abreu, K. N. M., Garcia, D. C., Hora, K. F. P. N. A, \& Souza, C. R. (2017). O teste de Cloze como instrumento de medida da proficiência em leitura: fatores linguísticos e não linguísticos. Revista de Estudos da Linguagem, Belo Horizonte, 25 (3), 1767-1799. Doi: 10.17851/2237-2083.25.3.1767-1799 Barbeiro, L. F. (2007). A aprendizagem da ortografia (1 ${ }^{\mathrm{a}}$ ed.). Lisboa: Edições ASA. 
Castro, R. A. (2008). Compreensão da leitura: Aplicação da técnica do procedimento Cloze nos ensinos fundamental e médio. Revista de Estudos Linguísticos e Literários, 1, 70-78.

Castro, S. L., Caló, S., Gomes, I., Kay, J., Lesser, R., \& Coltheart, M. (2007). PALPA-P, Provas de avaliação da linguagem e da afasia em português. Lisboa: CEGOC-TEA.

Cunha, N. B., \& Santos, A. A. (2009). Validade por processo de resposta no teste de Cloze. Fractal: Revista de Psicologia - UFF, 21 (3), 549-562. doi: ISSN: 0104-8023

Guidetti, A. A., \& Martinelli, S. C. (2007). Compreensão em leitura e desempenho em escrita de crianças do ensino fundamental. PSIC - Revista de Psicologia da Vetor Editora, 2 (8), 175-184. doi. ISSN 1676-7314.

Guimarães, S. R. K. (2011). Relações entre capacidade de segmentação lexical, consciência morfossintática e desempenho em leitura e escrita. Psicologia: Teoria e Pesquisa, 2 (1), 23-32.

Joly, M. C. R. A., \& Piovezan, N. M. (2011). Funcionamento diferencial dos itens do teste Cloze por opção. Arquivos Brasileiros de Psicologia, 63 (2), 58-68. doi: CEP: 22290-902.

Kongsuwan Nakul, K. (2015). Theoretical considerations of applications and implications of concordance-based cloze tests. Lit Linguist Computing, $30 \quad$ (4), 541-558. Doi: https://doi.org/10.1093/1lc/fqu033

Leal, T. F. (2013). Alfabetização: A aprendizagem e o ensino da leitura e da escrita. Rio de Janeiro: Ministério da Educação (Secretaria de Educação Básica).

Loh, F. C. H., \& Chia, N. K. H. (2013). Effectiveness of semantic cloze procedure to improve reading comprehension of weak readers in a primary school. Journal of the American Academy of Special Education Professionals, 73-118.

Ministério da Educação (2009). Programa de português do ensino básico. Lisboa: Ministério da Educação, Direção Geral de Inovação e Desenvolvimento Curricular.

Morais, G. A. (2005). Se a escrita alfabética é um sistema notacional (e não um código), que implicações isto tem para a alfabetização?. In A. Galvão, M. L. Coutinho, T. M. R. Leite \& R. P. Silva (Eds.), Alfabetização: A apropriação do sistema de escrita alfabética (pp. 29-46). Belo Horizonte: Autêntica.

Mota, M. M. P. E., \& Santos, A. A. A. (2014). O Cloze como instrumento de avaliação de leitura nas séries iniciais. Revista Quadrimestral da Associação Brasileira de Psicologia Escolar e Educacional, 18 (1), 135-142.

Peltzman, B. R. (2015). Reading instruction in America. North Caroline: McFarland \& Company, Inc.

Santos, A. A. (2004). O Cloze como técnica de diagnóstico e remediação da compreensão em leitura. Revista Interação em Psicologia, 8 (2), 217-226.

Silva, M. J. M., \& Santos, A. A. A. (2004). A avaliação da compreensão em leitura e o desempenho acadêmico de universitários. Psicologia em Estudos, 9 (3), 459-467.

Taylor, W. L. (1953). Cloze procedure: A new tool for measuring readability. Journalism Quarterly, 30, 415-433.

Veloso, A. J. (2005). A língua na escrita e a escrita da língua. Algumas considerações gerais sobre transparência e opacidade fonémicas na escrita do português e outras questões. Da investigação às práticas. Centro Interdisciplinar de Estudos Educacionais, VI (1), 49-69. 